\title{
Molecular Syndromology
}

\section{Cardiac Fibroma with Ventricular Tachycardia: An Unusual Clinical Presentation of Nevoid Basal Cell Carcinoma Syndrome}

\author{
Alyssa L. Ritter ${ }^{a, b}$ Eric J. Granquist ${ }^{d}$ V. Ramesh lyer ${ }^{b}$ Kosuke Izumi ${ }^{a, c}$ \\ Divisions of ${ }^{a}$ Human Genetics and ${ }^{b}$ Cardiology, Department of Pediatrics, and ${ }^{c}$ Division of Genomic Diagnostics, \\ Department of Pathology and Laboratory Medicine, The Children's Hospital of Philadelphia, and d Department of \\ Oral and Maxillofacial Surgery, University of Pennsylvania School of Dental Medicine, Philadelphia, PA, USA
}

\section{Established Facts}

- Pediatric cardiac tumors, while rare, are often associated with genetic conditions.

- Approximately $3 \%$ of individuals with nevoid basal cell carcinoma syndrome (NBCCS) have a cardiac fibroma.

- Cardiac fibromas in NBCCS typically present in infancy.

- Implementation of and adherence to management guidelines are crucial for patients with NBCCS due to the increased risk of malignancy.

\section{Novel Insights}

- The presenting feature of NBCCS can be cardiac fibroma.

- Careful examination of family and medical history of those with cardiac fibromas is necessary to make this crucial diagnosis.

\section{Keywords}

Arrhythmia · Cardiac fibroma · Cardiac tumor - Gorlin syndrome · Nevoid basal cell carcinoma syndrome .

Ventricular tachycardia

\section{Abstract}

Pediatric cardiac tumors are rare and often benign with an incidence of approximately $0.03-0.32 \%$ and can be associated with genetic conditions. For example, approximately
$3 \%$ of individuals with nevoid basal cell carcinoma syndrome (NBCCS), also known as Gorlin syndrome, have a cardiac fibroma. NBCCS is also characterized by lamellar or early calcification of the falx, jaw keratocysts, palmar and/or plantar pits, and a predisposition for basal cell carcinomas. Given the management implications of NBCCS, including appropriate cancer screenings and precautions, prompt identification of affected individuals is critical. We report a case of a 6-yearold female presenting with ventricular tachycardia secondary to cardiac fibroma. After diagnosis of recurrent jaw kera-

\section{KARGER}

(C) 2018 S. Karger AG, Basel

E-Mail karger@karger.com

www.karger.com/msy
Alyssa L. Ritter, MS, LCGC

Division of Human Genetics, Department of Pediatrics

The Children's Hospital of Philadelphia

3615 Civic Center Blvd., ARC 703E, Philadelphia, PA 19104 (USA)

E-Mail rittera@email.chop.edu 
tocysts, she was clinically and molecularly diagnosed with NBCCS. Identification of a cardiac fibroma should prompt careful assessment of past medical and family history with consideration of a diagnosis of NBCCS.

๑ 2018 S. Karger AG, Basel

Cardiac tumors in children are rare and often benign neoplasms with estimates of incidence ranging from 0.03 to $0.32 \%$ [Becker, 2000; Miyake et al., 2011; Linnemeier et al., 2015]. The most common types of cardiac tumor in pediatric populations are rhabdomyomas and fibromas. These tumors are often associated with genetic conditions, including the well-described association between cardiac rhabdomyomas and tuberous sclerosis [Becker, 2000; Northrup et al., 2015]. One such association is that between nevoid basal cell carcinoma syndrome (NBCCS), also known as Gorlin syndrome, and cardiac fibromas. Approximately $3 \%$ of individuals with NBCCS will develop a cardiac fibroma. NBCCS is also characterized by lamellar or early calcification of the falx, jaw keratocysts, palmar and/or plantar pits, and multiple and/or early-onset basal cell carcinomas [Gorlin, 2004; Bree et al., 2011; Huq et al., 2017; Evans and Farndon, 2018]. Characteristic facial features of NBCCS include macrocephaly, frontal bossing, and hypertelorism. The prevalence of NBCCS is estimated at approximately $1 / 30,000$ to $1 / 18,000$ [Evans et al., 2010; Evans and Farndon, 2018]. In the medical literature, there is one case report describing an 8-month-old infant with a family history of NBCCS who presented with ventricular tachycardia (VT) and left ventricular tumor, subsequently identified as a cardiac fibroma [Bossert et al.,
2006]. Herein, we report a case of a 6-year-old female presenting with VT secondary to a cardiac fibroma, with no known family history of NBCCS, who is subsequently clinically and molecularly diagnosed with NBCCS.

\section{Case Report and Results}

The 6-year-old patient presented to the emergency department with a rapid heart rate. EKG revealed a heart rate of 169 beats per minute in sustained VT. Transthoracic echocardiogram revealed depressed ventricular function consistent with tachycardia-induced cardiomyopathy and a ventricular tumor mass located along the atrioventricular groove posterior to the left atrium and left ventricle (Fig. 1). Her VT had both right and left bundle branch block morphologies on EKGs indicating different exit points along the ventricular septum (Fig. 2). The arrhythmia was initially not responsive to intravenous esmolol and lidocaine, but was subsequently controlled by intravenous procainamide. She was transitioned to oral amiodarone and nadalol with no recurrence of VT for the past 8 years. She also had a negative electrophysiological study with no inducible ventricular arrhythmias. Once stable, cardiac MRI was performed to better visualize the mass, which was determined to be 3.2 $\times 3.0 \times 2.9 \mathrm{~cm}$ in size and attached to the posterior aspect of the left ventricle, extending to the base of the left ventricle, and straddling the atrioventricular groove as well as protruding behind the left atrium (Fig. 3). Open biopsy and pathology of the mass revealed dense fibrous tissues composed of thick bands of collagen and scattered
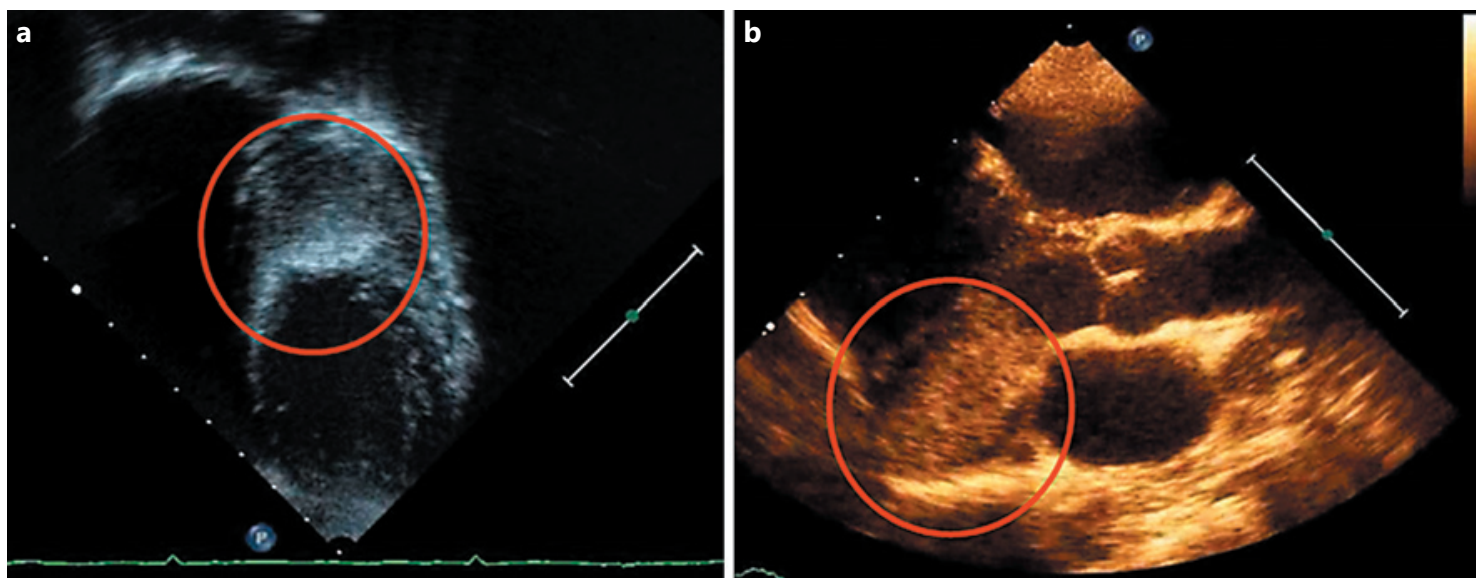

Fig. 1. Echocardiographic demonstration of the tumor (red circles) in 4-chamber (a) and parasternal long axis (b) views. 
fibroblasts with no cardiac muscle identified, consistent with a cardiac fibroma with no neoplastic transformation. The cardiac fibroma has remained stable in size per MRI and echocardiogram with no clinical evidence of arrhythmias.

At age 10, the patient was identified to have 3 mandibular cysts, which were asymptomatic and excised without complication. During orthodontic treatment at 13 years of age, a subsequent lesion of the mandible was identified. CT of the facial bones revealed multiple lucent lesions, 7 of which were excised and identified as odontogenic keratocysts by pathology (Fig. 4). The patient was then referred to Clinical Genetics with suspicion for NBCCS due to her history of multiple recurring odontogenic keratocysts.

The patient's prenatal, neonatal, and developmental histories were unremarkable. In addition to the health concerns noted above, she also has attention deficit hyperactivity disorder, anxiety, and depression, which are treated by medication and therapy. Physical examination at 13 years was significant for a prominent forehead, deep-set eyes, bulbous nasal tip, and multiple palmar pits (Fig. 5). The patient met clinical diagnostic criteria for

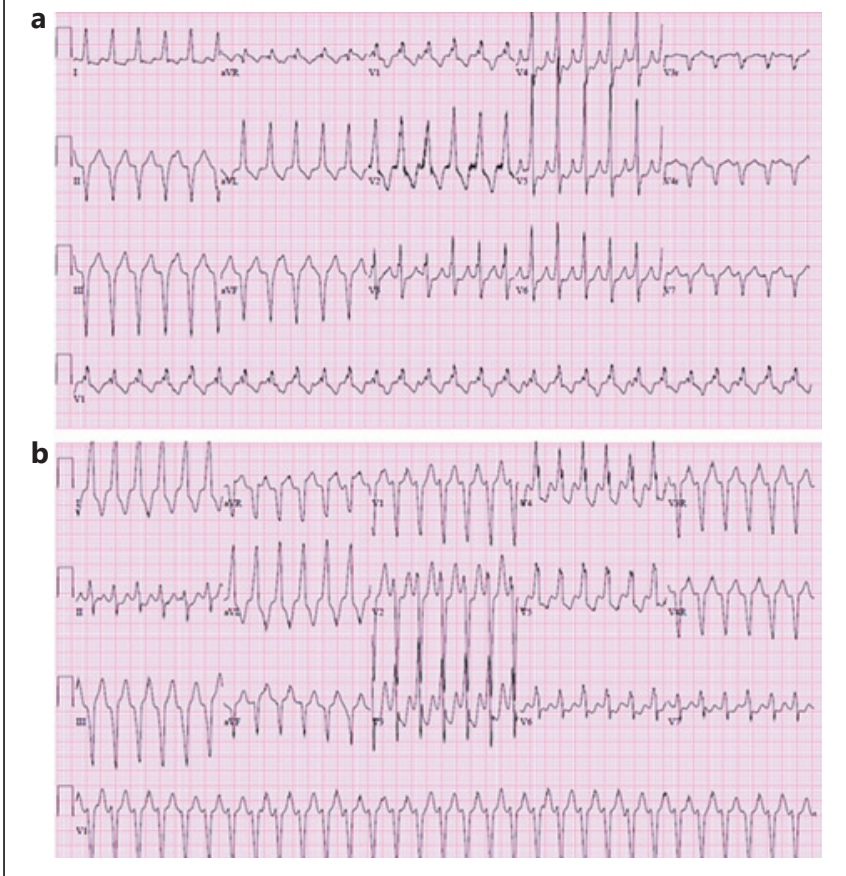

Fig. 2. Electrocardiograms from the patient showing ventricular tachycardia with right (a) and left bundle branch blocks (b).

Cardiac Fibroma and Nevoid Basal Cell Carcinoma Syndrome
NBCCS due to a history of multiple recurring odontogenic keratocysts, 2 or more palmar pits, and cardiac fibroma ( 2 major and 1 minor criteria) [Evans and Farndon, 2018]. Upon further review of the family history, the patient's father was noted to have recently diagnosed jaw cysts. Based on this clinical diagnosis, molecular confirmation by PTCH1 sequencing was recommended. A further review of the CT of her facial bones in light of this clinical diagnosis revealed small amounts of calcification in the anterior falx, confirming the presence of all 3 major clinical diagnostic criteria [Evans and Farndon, 2018].

The patient was identified to have a previously reported pathogenic missense variant in $\mathrm{PTCH} 1, \mathrm{c} .1526 \mathrm{G}>\mathrm{T}$

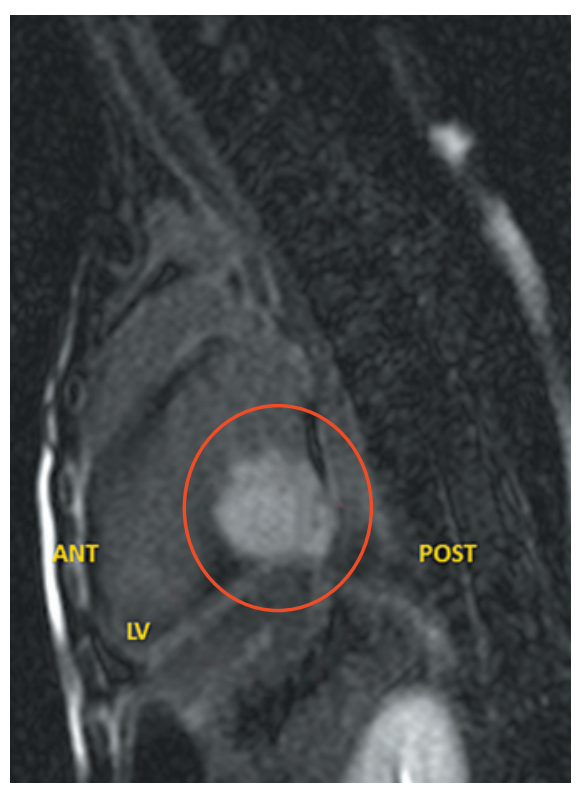

Fig. 3. Illustration of the tumor (red circle) by MRI in a longitudinal view. ANT, anterior; LV, left ventricle; POST, posterior.

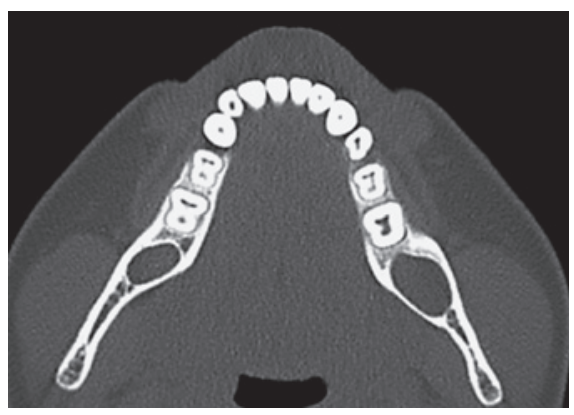

Fig. 4. Facial CT at 13 years demonstrating 2 separate odontogenic keratocysts, a feature rarely seen outside of a diagnosis of nevoid basal cell carcinoma syndrome.

Mol Syndromol 2018;9:219-223 221 
Fig. 5. Features of nevoid basal cell carcinoma syndrome evident on dysmorphology exam, demonstrating frontal bossing, deep-set eyes, bulbous nasal tip (a), and subtle palmar pitting (b).
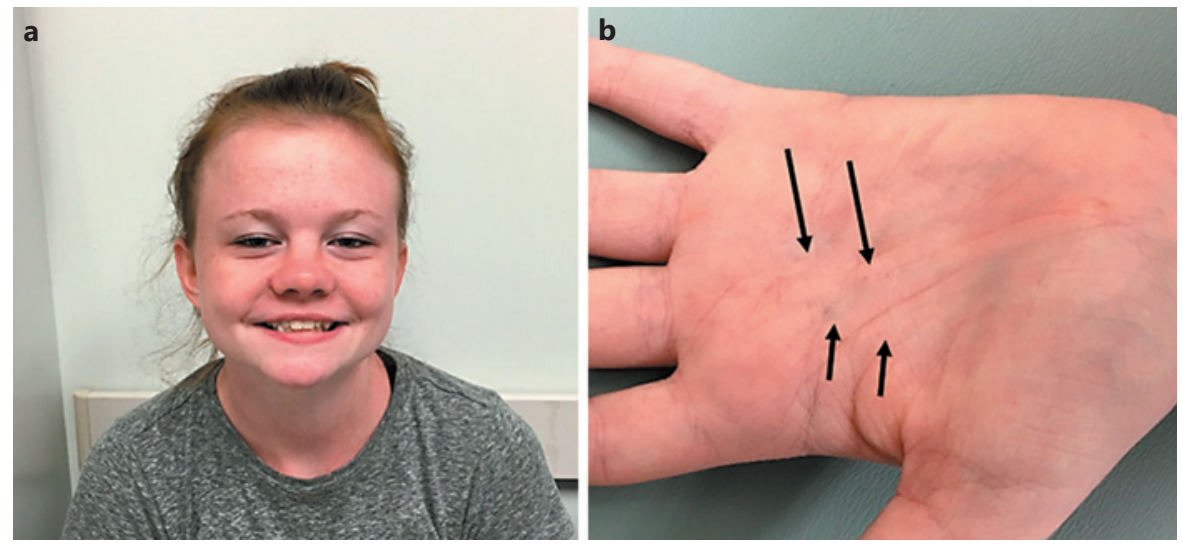

(p.Gly509Val). This variant was previously reported to segregate with NBCCs in a family, and other variants affecting this codon have been reported in association with NBCCS [Chidambaram et al., 1996]. The variant was not observed in a large population database (ExAC). Experimental studies of this variant showed activation of hedgehog signaling through a dominant negative mechanism consistent with the known mechanism of NBCCS [Hime et al., 2004; Pan et al., 2010].

\section{Discussion}

This case demonstrates an atypical presentation of NBCCS and an opportunity for early detection of this condition in other children with cardiac fibromas. NBCCS, also known as Gorlin syndrome, is characterized by lamellar or early calcification of the falx, jaw keratocysts, palmar and/or plantar pits, and multiple and/or early-onset basal cell carcinomas [Gorlin, 2004; Bree et al., 2011; Huq et al., 2017; Evans and Farndon, 2018]. NBCCS is most often inherited from an affected parent, though approximately $20-30 \%$ of the cases are de novo [Evans et al., 2010; Evans and Farndon, 2018]. Less commonly reported features of NBCCS include skeletal anomalies, early childhood medulloblastoma, cleft lip/ palate, and ovarian fibroma in women [Evans et al., 2017; Evans and Farndon, 2018].

Cardiac fibromas are found in approximately $3 \%$ of individuals with NBCCS [Gorlin, 2004; Evans et al., 2010; Evans and Farndon, 2018]. While typically presenting in infancy, and often associated with arrhythmias, cardiac fibromas have been reported to develop up to the age of 60 in individuals with NBCCS [Gorlin, 2004; Evans et al., 2010; Evans and Farndon, 2018]. In the medical literature, there is one case report describing an 8-month-old infant with a family history of NBCCS who presented with VT and left ventricular tumor, subsequently identified as a cardiac fibroma [Bossert et al., 2006]. Given the wide phenotypic spectrum of NBCCS, a high index of suspicion is required for making an early diagnosis of NBCCS. In light of the case reported herein, we propose that pediatric patients with cardiac fibromas should be carefully assessed for a diagnosis of NBCCS. Interestingly, somatic copy number variations of $P T C H 1$ have been reported in cardiac fibroma, suggesting the role of $P T C H 1$ in the pathogenesis of cardiac fibroma in general beyond NBCCS [Scanlan et al., 2008; Zhang et al., 2015].

Our case presented with a rarely identified manifestation of NBCCS and subsequently developed all 3 major diagnostic criteria for the condition. Given the age of diagnosis of her cardiac fibroma, she would not have been expected to show other hallmark features of the condition including jaw keratocysts or early-onset basal cell carcinomas [Evans et al., 2018]. She also presented with her cardiac fibroma outside of infancy, the typical time of diagnosis. The diagnosis of NBCCS in a proband allows for cascade genetic testing of other family members, impacting not just the medical management of the proband, but of the entire family. In light of the risk for basal cell carcinomas and early childhood medulloblastoma, identifying families with NBCCS is critically important in order to allow for appropriate cancer screenings in those at risk. Individuals with NBCCS are cautioned against ionizing radiation exposure, encouraged to apply sunscreen frequently, and to limit sun exposure [Bree et al., 2011]. Those under 8 years of age are recommended to have annual brain MRI with contrast in order to screen for medulloblastoma. Additionally, referrals for dermatologic, clinical genetics, developmental pediatrics, obstetric-gy- 
necologic and psychologic evaluations are all recommended for individuals with a new diagnosis of NBCCS. These recommendations are important for reducing basal cell carcinoma development, decreasing the risk for associated malignancies, and identifying potential complications of NBCCS early [Bree et al., 2011]. Additionally, cancer surveillance guidelines were recently published for individuals with NBCCS [Foulkes et al., 2017].

While rarely a presenting manifestation of NBCCS, cardiologists should have clinical suspicion and carefully evaluate for NBCCS when a child is identified with a cardiac fibroma. Early clinical recognition of NBCCS would facilitate the timely identification of basal cell carcinoma or medulloblastoma and implementation of surveillance guidelines. Therefore, assessment of personal and family history, with special attention to the presence of jaw cysts and basal cell carcinomas, should be performed in cases of cardiac fibromas in order to identify those with NBCCS and optimize their management.

\section{Statement of Ethics}

Informed consent for publication of history and photographs was obtained from all individual participants included in the study. The authors have no ethical conflicts to disclose.

\section{Disclosure Statement}

There are no conflicts of interest.

\section{References}

Becker AE: Primary heart tumors in the pediatric age group: a review of salient pathologic features relevant for clinicians. Pediatr Cardiol 21:317-323 (2000).

Bossert T, Walther T, Vondrys D, Gummert JF, Kostelka M, Mohr FW: Cardiac fibroma as an inherited manifestation of nevoid basal-cell carcinoma syndrome. Tex Heart Inst J 33:8890 (2006).

Bree AF, Shah MR, BCNS Colloquium Group: Consensus statement from the first international colloquium on basal cell nevus syndrome (BCNS). Am J Med Genet A 155A: 2091-2097 (2011).

Chidambaram A, Goldstein AM, Gailani MR, Gerrard B, Bale SJ, et al: Mutations in the human homologue of the Drosophila patched gene in Caucasian and African-American nevoid basal cell carcinoma syndrome patients. Cancer Res 56:4599-4601 (1996).

Evans DG, Farndon PA: Nevoid Basal Cell Carcinoma Syndrome, in Adam MP, Ardinger $\mathrm{HH}$, Pagon RA, Wallace SE, Bean LJH, et al (eds): GeneReviews ${ }^{\circledR}$ [Internet] (University of Washington, Seattle 1993-2018). Initial posting: Jun 20, 2002; last update: Mar 29, 2018.
Evans DG, Howard E, Giblin C, Clancy T, Spencer $\mathrm{H}$, et al: Birth incidence and prevalence of tumor-prone syndromes: estimates from a UK family genetic register service. Am J Med Genet A 152A:327-332 (2010).

-Evans DG, Oudit D, Smith MJ, Rutkowski D, Allan E, et al: First evidence of genotype-phenotype correlations in Gorlin syndrome. J Med Genet 54:530-536 (2017).

Foulkes WD, Kamihara J, Evans DGR, Brugières L, Bourdeaut F, et al: Cancer surveillance in Gorlin syndrome and rhabdoid tumor predisposition syndrome. Clin Cancer Res 23:e6267 (2017).

Gorlin RJ: Nevoid basal cell carcinoma (Gorlin) syndrome. Genet Med 6:530-539 (2004).

Hime GR, Lada H, Fietz MJ, Gillies S, Passmore A, et al: Functional analysis in Drosophila indicates that the NBCCS/PTCH1 mutation G509V results in activation of smoothened through a dominant-negative mechanism. Dev Dyn 229:780-790 (2004).

Huq AJ, Bogwitz M, Gorelik A, Winship IM, White SM, Trainer AH: Cohort study of Gorlin syndrome with emphasis on standardised phenotyping and quality of life assessment. Intern Med J 47:664-673 (2017).

-Linnemeier L, Benneyworth BD, Turrentine M, Rodefeld M, Brown J: Pediatric cardiac tumors: a 45-year, single-institution review. World J Pediatr Congenit Heart Surg 6:215219 (2015).
Miyake CY, Del Nido PJ, Alexander ME, Cecchin F, Berul CI, et al: Cardiac tumors and associated arrhythmias in pediatric patients, with observations on surgical therapy for ventricular tachycardia. J Am Coll Cardiol 58:19031909 (2011).

Northrup H, Koenig MK, Pearson DA, Au KS: Tuberous Sclerosis Complex, in Adam MP, Ardinger HH, Pagon RA, Wallace SE, Bean $\mathrm{LJH}$, et al (eds): GeneReviews ${ }^{\circledR}$ [Internet] (University of Washington, Seattle 19932018). Initial posting: Jul 13, 1999; last update: Sep 3, 2015.

Pan S, Dong Q, Sun LS, Li TJ: Mechanisms of inactivation of $P T C H 1$ gene in nevoid basal cell carcinoma syndrome: modification of the two-hit hypothesis. Clin Cancer Res 16:442450 (2010).

Scanlan D, Radio SJ, Nelson M, Zhou M, Streblow $\mathrm{R}$, et al: Loss of the PTCH1 gene locus in cardiac fibroma. Cardiovasc Pathol 17:93-97 (2008).

Zhang Q, Wang T, Wang D, Liu J, Yu W, et al: Somatic copy number losses on chromosome 9q21.33q22.33 encompassing the PTCH1 loci associated with cardiac fibroma. Cancer $\mathrm{Ge}$ net 208:615-620 (2015).
Cardiac Fibroma and Nevoid Basal Cell

Carcinoma Syndrome
Mol Syndromol 2018;9:219-223 DOI: $10.1159 / 000489056$ 